\title{
System Analysis of Energy Efficiency at Oil and Gas Industry Enterprises
}

\author{
A. V. Kulbyakina \\ Yuri Gagarin State Technical University of Saratov \\ Saratov, Russian Federation \\ e-mail: lenkova_av@rambler.ru
}

\author{
N.A. Ozerov \\ Yuri Gagarin State Technical University of Saratov \\ Saratov, Russian Federation \\ e-mail: nikita-alecseevich@yandex.ru
}

\begin{abstract}
The article discusses the methodological aspects of system analysis of energy efficiency of the oil and gas industry (OGI) enterprises. Modern OGI enterprises in large quantities consume all types of energy resources (ER) for their own needs. Therefore, issues of energy-saving and resources-saving, along with issues of environmental security are extremely important. The solution of such large-scale issues is possible on the basis of a systematic approach to the analysis, optimization and synthesis of complex systems, using mathematical modeling and algorithms of structural-parametric optimization. In accordance with the principles of system analysis, the scheme of internal and external energy flows, the mathematic description of structure of OIG enterprises, organizational diagram of energy-technological balances have been developed. The scheme of the own energy source with combined heat and electric power generation and utilization of combustible wastes is proposed. The results of feasibility study of the own energy supply sources are given.
\end{abstract}

Keywords - energy efficiency;oil and gas industry; hydrocarbon raw; system analysis

\section{INTRODUCTION}

Enterprises of OGI are complex chemical-technological systems which in large quantities consume all types of ER for their own needs. The energy component in the final product cost reaches $11-15 \%$ with a negative trend of increase in recent years. At the same time, the most enterprises have great potential for energy saving (tabl.1).

TABLE I. POTENTIAL FOR ENERGY SAVING OF OIL AND GAS INDUSTRY ENTERPRISES OF RUSSIAN FEDERATION (2010-2020 YEARS)

\begin{tabular}{|l|c|c|c|}
\hline Enterprises activity & $\begin{array}{c}\text { Natural Gas } \\
10^{6} \mathrm{~m}^{3}\end{array}$ & $\begin{array}{c}\text { Electric } \\
\text { Energy } \\
10^{6} \mathrm{kWh}\end{array}$ & $\begin{array}{c}\text { Thermal } \\
\text { Energy } \\
10^{3} \mathrm{GJ}\end{array}$ \\
\hline Gas, gas condensate, oil production & 4557 & 302 & 2028 \\
\hline Gas transportation & 17131 & 3446 & 5447 \\
\hline Raw hydrocarbon processing & 1626 & 883 & 18855 \\
\hline
\end{tabular}

However, the realization of this potential has not yet been achieved for many reasons on the all type of the enterprises of OGI. In terms of technology and energy consumption this enterprises have common characteristics such as:
- inextricable relationship between the process system (PS) and the internal energy supply system (IESS);

- a large number of secondary energy resources, combined with environmental pollution;

- a significant number and uniformity of industrial wastes, effluents, gas emissions.

The most significant at present for the OGI enterprises are the issues of environmental safety, the useful use of secondary energy resources, and integrated waste management. But apart from this for the Russian OIG enterprises, the issues of increasing the depth of processing of hydrocarbon raw and reducing the specific energy consumption for output of products, which more than double the indices of industrially developed countries, require a lot of attention.

Taking into account the current situation in the oil and gas complex, the task of implementation the principles of energy saving, resource saving, environmental safety with common energy efficiency and optimizing operation mods is extremely topical.

The solution of such large-scale issues is possible on the basis of a system approach to the analysis, optimization and synthesis of complex systems, using mathematical modeling and algorithms of structural-parametric optimization [1-3].

\section{METHODOLOGICAL ASPECTS OF SYSTEM AHALYSIS OF ENTERPRISES OF OIL AND GAS INDUSTRY}

\section{A. General Description of the Internal Energy Supply System of Enterprises of Oil and Gas Industry}

Petrochemical facilities and raw hydrocarbon processing plants (RHPP) - oil refineries and gas processing plants (GPP) - are usually characterized by the most complex technological structure. Their structure is formed by PS and a widely integrated IESS through continuous process of raw processing and energy resources consuming/generating. The IESS includes several basic subsystems. They are a fuel supply system, an electrical supply system, a heat supply system. The fuel supply system has the largest number of interrelations with the PS and with the external energy supply system. Fig. 1 shows internal and external interrelations of the fuel supply system. 
The main fuel users at the RHPP are furnaces, burning engineering equipment, thermal waste treatment plants, flaring systems, boilers. To provide liquid or gaseous fuels, at the RHPP there is a fuel-handling facility, including fuel preparation shops, fuel loopback pipes with continuously circulating liquid fuel, with laid lines for separate technical facilities. There is also heat exchange equipment for the preheating of fuel before it is fed into the furnace burners.

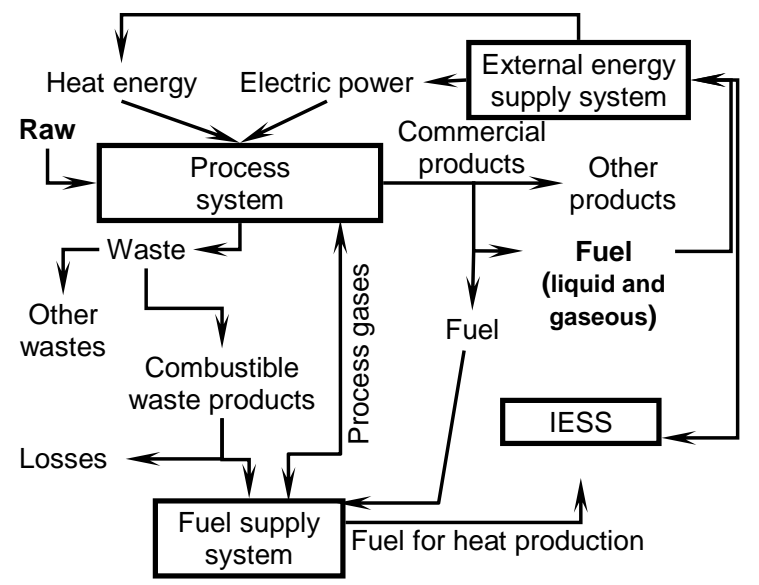

Fig. 1. Scheme of relationships of the fuel supply system with PS and IESS

Despite the significant similarities in the processes of GPP and refineries, their fuel supply systems have substantial differences. Thus, gas from the commercial gas network, as well as hydrocarbon gases obtained during the processing of raw materials, is the main fuel for the GPP. The refineries have a large amount of own generation of liquid fuel, refinery gases, and the commercial gas is usually a third-party ER. For the current domestic refinery, the percentage distribution of the fuel used in some processes is shown in table 2.

TABLE II. PERECENTAGE OF FUEL USED IN THE PROCESSES OF REFINERY

\begin{tabular}{|l|c|c|c|c|}
\hline \multirow{2}{*}{ Technological process } & \multicolumn{4}{|c|}{ Type of energy resources } \\
\cline { 2 - 5 } & $\begin{array}{c}\text { Own } \\
\text { gas, \% }\end{array}$ & $\begin{array}{c}\text { Natural } \\
\text { gas, \% }\end{array}$ & $\begin{array}{c}\text { Fuel } \\
\text { oil, \% }\end{array}$ & $\begin{array}{c}\text { Coke } \\
\text { (conversed } \\
\text { fuel), \% }\end{array}$ \\
\hline $\begin{array}{l}\text { Primary distillation } \\
\text { (crude vacuum unit) }\end{array}$ & 75 & 15 & 10 & - \\
\hline Thermal cracking & 80 & 5 & 15 & - \\
\hline Catalytic cracking & 43 & 6 & 25 & 26 \\
\hline Hydrotreating & 99.5 & 0.4 & 0.1 & - \\
\hline
\end{tabular}

As it can be seen from the table, its own fuel (refinery gas, fuel oil and conversed fuel) accounts for a large share of the consumption, while the share of natural gas ranges from 0.5 to $20 \%$ for all technological processes.

The analysis of the scheme (Fig.1) and the table data reveals that the main ways of the energy and fuel efficiency increasing are associated with the maximum usage of own fuel and comprehensive utilization of combustible waste. Such solutions will allow optimizing fuel consumption in the PS and reducing the consumption of commercial or third-party gas as fuel, as well as reducing the harmful impact on the environment.

The improvement of the OGI enterprises with the implementation of energy and resource saving principles and environmental safety is possible with the integrated approach, based on the principles of system analysis and mathematic modelling.

\section{B. The System Analysis Approagch of Energy Supply Systems of Oil and Gas Industy Enterprises}

The system analysis of the IESS and its components involves the following stages: defining the structure of the object and its operating parameters; developing and calculating characteristics and efficiency factors; the identification of influential factors and their impact on modes of operation. [4] The synthesis of the energy efficient IESS is primarily to define the principles underlying its operation, to develop a rational structure and the parameters of the fuel system; to model mathematically structure alternatives; to develop a set of engineering solutions to improve the efficiency of the fuel system.

A formal description of the structure of the RHPP (as the most complex structure) power engineering balance (fig. 1), to solve the problems of improving the efficiency of the fuel system, represents the aggregation of multiple structure models:

$$
\begin{aligned}
& N \text { PS processing } P_{P S}=P_{P S}^{1} \ldots P_{P S}^{N} \\
& M \text { IESS subsystems } P_{I E S S}=P_{I E S S}^{1} \ldots P_{I E S S}^{M} \\
& \text { RHPP as a whole } R H P P=P_{P S} \cup P_{I E S S}
\end{aligned}
$$

where $P_{P S}^{1} \ldots P_{P S}^{N}$ is the mathematical description of the structure of $\mathrm{RH}$ preparation and processing, waste recycling, conditioning and storage of intermediate and final technological flows, transportation of products;

$P_{\text {IESS }}^{1} \ldots P_{\text {IESS }}^{M}$ is the mathematical description of the structure of the IESS subsystems that generate, transform, transport fuel, electricity, thermal energy, water, in-plant energy supplies.

The system of mathematical models for calculating the energy-technological balance has been developed in accordance with the equations of a formalized description of the structure of the RHPP (1)-(3). The developed system of mathematic models includes models of calculation ER production/consumption at all levels of the hierarchy from facilities to units.

The level of technological processes:

- $\mathrm{J}$ technological processes of the PS

$$
T P_{P S}=T P_{P S}^{1}, \ldots, T P_{P S}^{j}, \ldots T P_{P S}^{J}
$$

- I technological processes of the IESS: 


$$
T P_{I E S S}=T P_{I E S S}^{1}, \ldots, T P_{I E S S}^{i}, \ldots T P_{I E S S}^{I}
$$

where $T P_{P S}^{1}, T P_{P S}^{j}, T P_{P S}^{J}$ are the mathematical descriptions of processes of production;

$T P_{\text {IESS }}^{1}, T P_{I E S S}^{i}, T P_{\text {IESS }}^{I}$ are the mathematical descriptions of the production, consumption, conversion, transfer of ER.

The level of facilities and units:

- $\mathrm{K}$ units of the PS

$$
U_{P S}=U_{P S}^{1}, \ldots, U_{P S}^{k}, \ldots U_{P S}^{K} ;
$$

- $\quad$ L units of the IESS

$$
U_{I E S S}=U_{I E S S}^{1}, \ldots, U_{I E S S}^{k}, \ldots U_{I E S S}^{K}
$$

where $U_{P S}^{1}, U_{P S}^{k}, U_{P S}^{K}$ are mathematical descriptions of facilities and units of the PS;

$U_{\text {IESS }}^{1}, U_{\text {IESS }}^{k}, U_{\text {IESS }}^{K}$ are mathematical descriptions of facilities and units of the IESS.

The mathematical description of processes for certain types of ER enters into set (4) and set (5) simultaneously. Thus, the intersection of sets $T P_{P S}$ and $T P_{I E S S}$ is not an empty set:

$$
T P_{P S} \cap T P_{I E S S} \neq \varnothing
$$

The same is true for the mathematical description of facilities and units of the PS and the IESS:

$$
U_{P S} \cap U_{I E S S} \neq \varnothing
$$

The models of calculations material and energy balances are main elements of mathematical descriptions (1)-(9). These models have been developed using structure analysis and design technique SADT.

\section{The mathematic modelling of Energy Supply Systems of Oil and Gas Industy Enterprises}

Mathematical modelling is an important aspect of system analysis of enterprise performance [5 - 7]. In general terms, the mathematical model of the IESS, depending on the influencing factors can be written:

$$
\bar{Y}=\bar{F}(\bar{X}, T, \bar{D}, \bar{P}, \bar{O}, \tau)
$$

where $\bar{Y}, \bar{X}$ are the vectors of output and input variables, respectively;

$\bar{F}$ - the vector function of vector arguments $\bar{X}, \bar{D}, \bar{P}, \bar{O}$ and scalar argument $\tau$ (time); $T$ - the process topology; $\bar{D}$ - the vector of structural parameters; $\bar{P}$ - the vector of the technological parameters; $\bar{O}$ - the parameter vector of the element process mode.
The mathematical model of the fuel system efficiency, which is a quality indicator of its operation, is written in general terms as follows:

$$
k=k(T, \bar{D}, \bar{P}, \bar{O}, \bar{S}, \tau)
$$

where $k$ is the efficiency coefficient, $\bar{S}$ is the vector of system properties;

The use of mathematical modelling, the strategy for applying the principles and methods of the system analysis, synthesis and optimization to solve the problems of synthesizing the optimum structure of the fuel system are based on the mathematical models of the fuel system $(10,11)$.

The use of the mathematical models with specified vector of input parameters $\mathrm{X}$ and chosen efficiency criteria with required accuracy allows defining output variables $Y$, evaluating the system properties and values of the fuel system efficiency. Function model of energy-technological balance have been developed in the form of an organizational diagram with using developed mathematical description of the IESS and the PS (fig. 2).

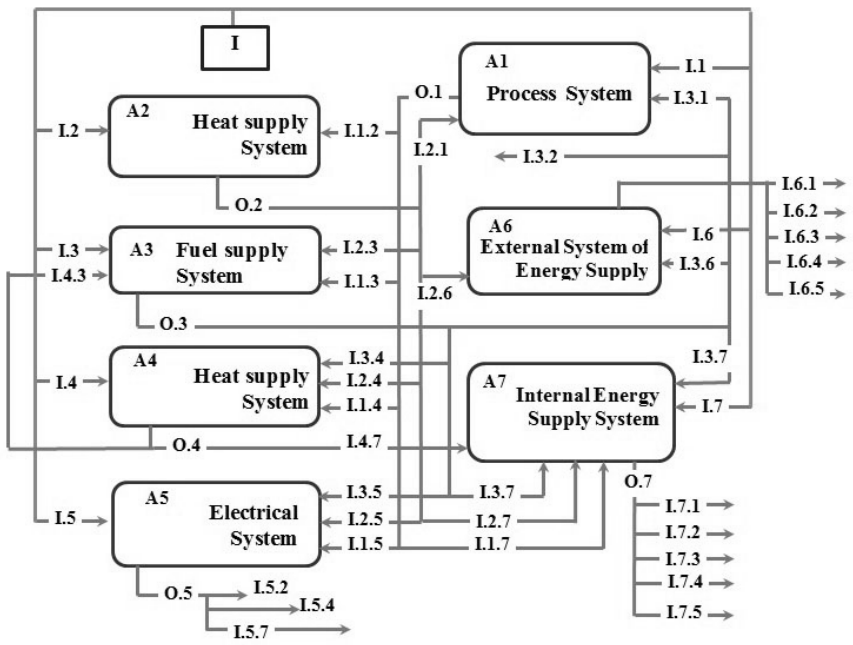

Fig. 2. Organizational diagram of energy-technological balance of OGI enterprises.

I - incoming data, parameters of elements A1, A2, A3, A4, A5, HR parameters, characteristics of the external system of energy supply; I= (I.1, I.2, I.3, I.4, I.5, I.6, I.7);

O.1 $=(\mathrm{I} .1 .2, \mathrm{I} .1 .3, \mathrm{I} .1 .4, \mathrm{I} .1 .5, \mathrm{I} .1 .7)-$ parameters of the PS and processes flows calculated from the material balance of the PS, necessary for blocks A1-A5, A7.

$\mathrm{O} .2=(\mathrm{I} .2 .2, \mathrm{I} .2 .3, \mathrm{I} .2 .4, \mathrm{I} .2 .5$, , I.2.6, I.2.7) - heat flows of the heat supply system; the total flow of heat energy generated and consumed in the PS and the IESS;

O.3 = (I.3.1, I.3.2, I.3.4, I.3.5, I.3.6, I.3.7) - fuel consumption - own fuel (liquid and gaseous) and fuel of the external system of energy supply - in the PS and the IESS;

O.4 = (I.4.3, I.4.7) - power flows of the electrical system; the total amount of electricity generated and consumed in the PS and IESS, taking into account losses in the power supply system; 
O.5 = (I.5.2, I.5.4, I.5.7) - process water flows necessary for calculation of IESS subsystem balances;

O.6 = (I.6.1, I.6.2, I.6.4, I.6.5) - the amount of ER supplied from the external system of energy supply, taking into account losses in the networks;

O.7 = (I.7.1, I.7.2, I.7.3, I.7.4, I.7.5) - energy flows from the IESS to the PS and to the all subsystems.

The developed organizational diagram of energytechnological balance is the base for creating diagrams of its individual elements, mathematic models and software of calculation of ER consumption/generation.

The organizational diagram of energy-technological balance is element of structural-parametric optimization of the object. Directions of OGI enterprises development and certain engineering solution have been suggested by developed system analysis approach and mathematic modelling.

\section{OWN ENERGY SOURCES OF ENTERPRISES OF OIL AND GAS INDUSTRY}

As one of the promising ways for increasing the efficient of the IESS of OGI enterprises, it is proposed to develop and implement own sources of energy supply. The own sources of energy allow not only to generate the necessary energy resources, but also to utilize combustible gaseous and wastewater. The prospect of creating own energy sources is due to a number of external and internal factors. External factors include such as an increase in energy tariffs, an insufficient level of reliability of energy supply, a shortage of generating capacities in many regions of the country [8-11]. Among the most significant internal factors can be identified such as high energy consumption, a significant amount of oil waste, the availability of unused secondary energy resources. Three main design principles have been chosen for implementation from a variety of possible principles $P$ $(\pi \in P)$, when designing their own sources of energy supply. These principles are used as a basis for optimization of the IESS of OGI enterprises as a whole. There are $\pi_{1}$ - maximum closure of the IESS with the utilization of secondary energy recourses and wastes; $\pi_{2}$ - environmental safety; $\pi_{3}$ reliability of energy supply.

The solution of the problem of creating the own energy source and optimizing the IESS with the implementation of these principles is represented by schematic diagram (fig. 3).

The proposed source of energy on the basis of gas turbine units is integrated with the processes and facilities of the PS and IESS and the water supply system. Generation of electric and heat energy takes place in a combined-cycle plant at GTU and STU. Heat energy generated at WHB and goes to $\mathrm{HC}$ as hot water and steam. In turn, the UTU allows disposing wastes that is usually in large quantities present in the enterprises of OGI. Such wastes include hydrocarbon gases and oilcontaining industrial effluents. High-temperature flue gases enter the WHR from process units and the UTU. This makes it possible to generate steam in the WHB, which is used in a steam turbine as a working fluid.

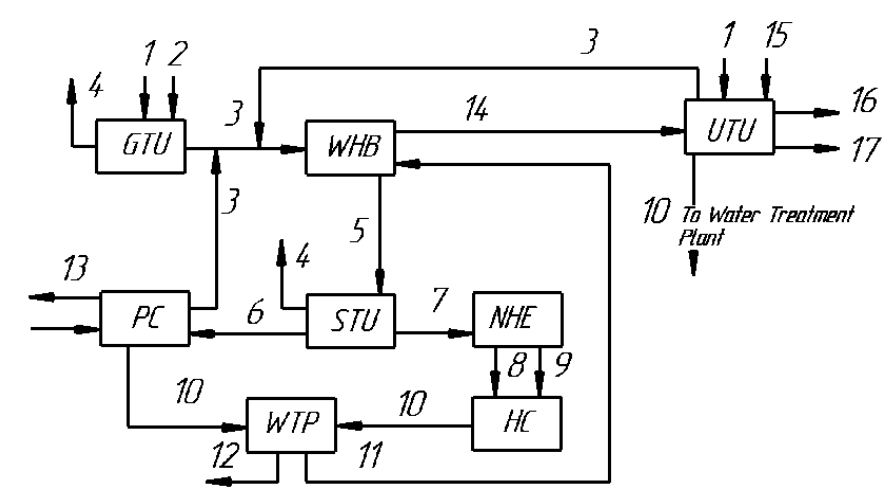

Units: GTU - a gas turbine unit; WHB - a waste heat boiler; STU - a steam turbine unit; PC - a processes consumer; NHE - a network heat exchanger; HC - a heat consumer; WTP - a water treatment plant; UTU - a unit of thermal utility. Flows: 1- fuel; 2 - air; 3 high-temperature flue gases; 4 - electric power; 5 - 7 - steam (5 steam to STU; steam to PC; 6 - steam to NHE); 8,9 - heating load and hot water supply; 10 - water condensate; 11 - pure water; 12 water into the domestic consumption system; 13 - process flow; 14 outgoing flue gases.

Fig. 3. Schematic diagram of own energy source integrated with the IESS and the PS of OGI enterprises.

Thus, the main advantages of the scheme are:

- combined heat and power generation at the GTU and the STU;

- neutralization and utilization of hydrocarboncontaining gases and wastes at the UTU;

- utilization of the potential of high-temperature flue gases from the PS units and from the UTU;

- use of water vapor from the exhaust flue gases in the WTP.

The developed own energy source implements the principles of energy and recourses saving; maximally closed IESS; environmental safety; reliability.

\section{RESULTS OF NUMERICAL EXPERIMENTS}

The choice of specific main and auxiliary equipment of the own energy sources depends on a significant number of factors. There are concrete technological structure of the object; stage of its life cycle; operation mods; climatic conditions. The developed aspects of the system analysis and mathematic modelling take into account the effect of influencing factors. Based on the developed theoretical approaches, variants of modernization of the IESS of the existing domestic refinery with the introduction of its own energy source have been proposed. Several variants of hardware design of the own energy source have been considered.

As one of the indicators of the effectiveness of the own energy source with thermal utilization have been adopted the coefficients of rationalization of balances:

energy-technology $\quad K_{R E T B}=1-\left(E_{S}^{R} / E_{S}^{N}\right)$; 
fuel

$$
K_{R F}=1-\left(E_{E O G I}^{R} / E_{E O G I}^{N}\right)
$$

water consumption $K_{R W}=1-\left(W_{E O G I}^{R} / W_{E O G I}^{N}\right)$;

drainage

$$
K_{R D}=1-\left(D_{E O G I}^{R} / D_{E O G I}^{N}\right),
$$

where $E_{S}^{R}, E_{S}^{N}, E_{E O G I}^{R}, E_{E O G I}^{N}$ - specific energy capacity calculated on the basis of normal and rational energytechnology and fuel balances; $W_{E O G I}^{N}, D_{E O G I}^{N}, W_{E O G I}^{R}, D_{E O G I}^{R}$ respectively, the specific water consumption and drainage for the normalized and optimal version of the IESS.

In the course of the analysis it was found that the most effective is the scheme based on combined-cycle gas turbine power plant with the following composition of the main equipment: 2 gas turbines SGT-400 (Cyclone) Alstome; 2 waste heat recovery boilers KGT-24/1.3-250 and 1 steam turbines $\mathrm{P}-1,3 / 0,6$. The investment project for the creation and operation of the own energy source in the IESS structure of a given hardware design has the following key performance indicators:

TABLE III. FEASIBILITY STUDY

\begin{tabular}{|l|c|}
\hline Electric Capacity, MW & 26.3 \\
\hline Thermal capacity, MW & 36.5 \\
\hline Profitability index & 2.23 \\
\hline Integral effect (for 15 years), million dollars & 46,5 \\
\hline Payback period, years & 5 \\
\hline Coefficients of rationalization of energy consumption & 0.267 \\
\hline Coefficients of rationalization of water consumption balance & 0.901 \\
\hline Coefficients of rationalization of drinage balance & 0.967 \\
\hline
\end{tabular}

The analysis of table data reveals that introduction of the own energy source is economically justified. The efficient of the project is also related to the reduction of environmental costs due to thermal neutralization of gases and wastewater in the UTU.

\section{RESULT DISCUSSION}

Set options of the own sources have been designed and evaluated on the basis of the developed theoretical positions of the system analysis and mathematic modeling. For individual processes in the enterprises of OGI, application of the proposed energy supply options with the optimization of the IESS results in a significant economic impact and reduces the ER consumption, including fuel for its own needs.

\section{CONCLUSIONS}

1. Methodological aspects for system analysis of the enterprises of OGI IESS have been defined including the mathematic description of its structure, organizational diagram of energy-technological balance, mathematical model of its elements.

2. Areas of modernization and development of energy supply system of the OGI enterprises scientifically substantiated.

3. The scheme of the own energy source with combined heat and electric power generation and utilization of combustible wastes is proposed.

4. The technical and economic indicators for the implementation of solutions to develop efficient energy supply system at the enterprises of OGI have been given.

\section{Acknowledgment}

The work was supported by the grant of the Russian Science Foundation (project №17-79-10134).

\section{References}

[1] I.V. Dolotowsky and A.V. Kulbjakina, "The structural and parametric optimization algorithms of the energy complex enterprises for hydrocarbon preparation and transportation", Avtomatizatsij. Sovremennie technologii (Automation. Modern tenology), vol.11, 2016, pp 10-15.

[2] D.V. Sokolov., V.A. Stennikov, T.B.Oshchepkova and Ye.A. Barakhtenko, "The new generation of the software system used for the schematic-parametric optimization of multiple-circuit heat supply systems", Thermal Engineering. 2012. vol. 59. № 4. pp. 337-343.

[3] V.A. Stennikov, E.A. Barakhtenko and D.V. Sokolov, "Use of multilevel modeling for determining optimal parameters of heat supply systems", Thermal Engineering. 2017. vol. 64. № 7. pp. 518-525.

[4] A.V. Kulbjakina and I.V. Dolotowsky, "Methodological aspects of fuel performance system analysis at raw hydrocarbon processing plants" IOP Conf. Series: Journal of Physics: Conf. Series 944 (2017) 012068

[5] S. AlSaqoor, A. Alahmer, F. Al Quran, A. Andruszkiewicz, K. Kubas, P. Regucki and W. Wędrychowicz, "Numerical modeling for the retrofit of the hydraulic cooling subsystems in operating power plant", Thermal Engineering. 2017.Vol. 64. № 8. pp. 551-558.

[6] A.A. Aleksandrov, I.A. Arkharov, E.S. Navasardyan and E.A. Antonov "Modeling of processes in microcryogenic gas machines", Chemical and Petroleum Engineering. 2015. vol. 10. pp. 3-6.

[7] Y.A. Radin, T.S. Kontorovich and K.A. Molchanov, "The effectiveness of combined-cycle power plants hot startups simulating", Thermal Engineering. 2015. vol. 62. № 9. pp. 630-635.

[8] A.A. Makarov, F.V. Veselov, A.S. Makarova, T.V. Novikova and T.G. Pankrushina, "Strategic prospects of the electric power industry of Russia”, Thermal Engineering. 2017. vol. 64. № 11. pp. 817-828.

[9] F.V. Veselov, I.V. Erokhina, A.S. Makarova and A.A. Khorshev, “ Comprehensive assessment of the effective scope of modernization of thermal power plants to substantiate the rational structure of the generating capacities for the future until 2035", Thermal Engineering. 2017. vol. 64. № 3. pp. 161-169.

[10] A.S. Makarova, T.G. Pankrushina, L.V. Urvantseva and A.A. Khorshev, "Combined heat and power in the draft of the new Russian energy strategy”, Thermal Engineering. 2015. vol. 62. № 6. pp. 389-395.

[11] E.K. Arakelyan, A.V. Andriushin, S.Y. Burtsev, K.A. Andriushin and S.R. Hurshudyan, "Methodology for consideration of specific features of combined-cycle plants with the optimal sharing of the thermal and the electric loads at combined heat power plants with equipment of a complex configuration”, Thermal Engineering. 2015. vol. 62. № 5. pp. 335-340.. 